\title{
Effect of Educational Program on Knowledge and Practices of Maternity Nurses regarding Cardiotocography
}

Saleh Zaghir Mohammed Alhetar ${ }^{1}$, Soad Abd-Elsalam Ramadan ${ }^{2}$, Hend Abdallah EL Sayed Afifi $^{3}$, and Samah Abdelhaliem Said Ibrahim ${ }^{4}$

(1) Demonstrator, Faculty of Medicine and Health Sciences/ Nursing Department, Taiz University, Yemen, (2) Professor of Obstetrics Gynecological Nursing, Faculty of Nursing/ Benha University and $(3,4)$ Assistant Professor of Obstetrics Gynecological Nursing, Faculty of Nursing/ Benha University.

\section{Abstract}

Background: Monitoring and recording fetal heart rate by cardiotocography is to detect any changes that might occur that put the fetus at risk of fetal distress or death due to lack oxygen. Aim of study: Was to evaluate the effect of educational program on knowledge and practices of maternity nurses regarding cardiotocography. Design: A quasi-experimental design (Time series design) was utilized to fulfil the aim of the study. Sample: A convenient sample of 40 maternity nurses were included in the present study. Setting: The present study was conducted at Labor and Cardiotocography room of the Obstetrics and Gynecological department at Benha University Hospital. Tools of data collection: Self-administered questionnaire, and nurses' observational checklist regarding cardiotocography. Results: The majority of nurses were had poor level of knowledge and unsatisfactory practice during pre-program, while during post program, and followup the majority of nurses were had good level of knowledge and satisfactory practice, with slightly decline during after 3 months follow-up. Conclusion: Educational program had a positive effect on improving knowledge and practice of maternity nurses regarding cardiotocography. Recommendations: Applying of continuous in-service training program for maternity nurses to improve performance regarding cardiotocography.

Keywords: Cardiotocography, Educational Program, Knowledge, Practice.

\section{Introduction}

Pregnancy is a wonderful natural experience that is part of every woman's life cycle. The health of the mother and fetus is closely linked. Recurrent fetal heart monitoring during pregnancy and labor gives an impression of fetal well-being, thus promoting the health status of newborns after birth. There are different techniques used to assess fetal well-being, ranging from simple maternal evaluation of fetal movement to more complex diagnostic tests guided by ultrasound (Cecil, 2020).

Fetal heart rate monitoring is recommended for women with gestational hypertension, gestational diabetes, obesity, and maternal age more than or equal to 40 , maternal pyrexia, and pre-dermal anesthesia (Kahveci et al., 2018). Assessment of fetal well-being can be done through intermittent auscultation, which is used for women at the onset of labor and having a low risk of developing fetal compromise. Also, continuous monitoring as external Cardiotocography (CTG) is recommended for women having risk factors or fetal compromise that are identified antenatal and detected at the onset of labor (Tamber et al., 2020). 


\section{Cardiotocography}

There are two methods of fetal heart rate monitoring in labor. Auscultation is a method of periodically listening to the fetal heartbeat. Electronic fetal monitoring is a procedure in which instruments are used to continuously record the heartbeat of the fetus and the contractions of the woman's uterus during labor. The method that is used depends on the policy of the hospital, the risk of problems, and how labor is going. If there are not any complications or risk factors for problems during labor, either method is acceptable (Rodgers, 2020).

The evidence for the benefits of continuous CTG monitoring, as compared with intermittent auscultation, in both lowand high-risk labors is scientifically inconclusive (Bertrand and consortium., 2019).

Furthermore, cardiotocography is a fetal monitoring system that records the fetal heart rate through a transducer fixed on the mother's abdomen and the uterine contractions through a transducer placed at the fundus. The main objective of recording fetal heart rate by CTG is to detect any changes that might occur that put the fetus at risk of death or distress. Also, it prevents intrapartum fetal death and reduces long-term neurological disorders and neonatal seizures (Holmgren, 2020).

A normal CTG is reassuring regarding the state of fetal oxygenation as hypoxia/acidosis is generally restricted to cases with suspicious or pathological patterns. However, a large number of fetuses with the latter patterns will not have clinically important hypoxia/acidosis (Visser and Ayres-de-Campos, 2017).

Due to false-positive cases and unnecessary medical interventions, adjunctive technologies have been proposed to further assess fetal oxygenation. These technologies should indicate intervention at an early stage of evolving fetal hypoxia/acidosis to prevent rather than to predict poor newborn outcomes. Several adjunctive technologies including fetal blood sampling, continuous $\mathrm{pH}$ and lactate monitoring, fetal stimulation, and pulse oximetry, have been successfully established (Richards, 2020).

Preventable harm linked to childbirth can be disastrous for women, children, and families. Intrapartum fetal monitoring is aimed to identify fetal compromise and facilitate the right action in response. However, suboptimal practice, mainly in relation to electronic fetal heart rate monitoring using cardiotocography in labour, is a known problem and remains frequently cited in successful obstetric malpractice claims. Training of maternity personnel remains the most frequently recommended intervention to improve electronic fetal monitoring (Kelly et al., 2020).

Lack of knowledge can increase the anxiety levels of both the nurse and woman. Nurses have responsibilities for recognizing and interrupting fetal monitoring patterns, notifying the physician of the problems, and initiating corrective and supportive measures when needed (Blix et al., 2019).

Nurses are those professionals who spend a lot of time with the mother during labor, hence nurses need to be competent enough to perform and interpret the tracings correctly and timely in order to promote the measures in reducing fetal death. In addition, cardiotocography educational program are conducted worldwide especially abroad as an in-service or continuing nursing education program, but not much flourished in Egypt to empower the maternity nurses to be competent enough in cardiotocography interpretation (Wisner and Holschuh, 2018).

\section{Significance of the study}

The major cause of perinatal mortality is inadequate monitoring and care during labor by skilled health professionals. 
According to WHO 2017, perinatal deaths have decreased from 4.6 million in 1990 to 3.3 million in 2010. It is identified that $99 \%$ of the perinatal mortality occurs in developing countries (Rosy, 2018).

Intra Uterine Growth Retardation (IUGR) occurs when the fetus is deficient in necessary nutrition or because of infections. IUGR can also occur due to the reduction of fetomaternal respiratory exchange. Abnormalities in fetal heart rate, fetal movement, and fetal kick count patterns also indicate fetal well-being. Currently, the main focus of maternal and fetus health is towards the evaluation of fetal health that is to assess fetal well-being. Because the majority of $80 \%$ of fetal death occurs in the antepartum period due to various causes which include chronic fetal hypoxia, intrauterine growth retardation, maternal complications, diabetes mellitus, hypertension, infection, and fetal congenital malformation (Sergi, 2020).

The clinical experience of the researcher found that nurses had inadequate knowledge and unsatisfactory practices regarding cardio-tocography. Hence, this study was conducted to assess the effect of educational program on the knowledge and practices of maternity nurses regarding cardiotocography.

\section{Aim of the study}

This study aimed to evaluate the effect of educational program on knowledge and practices of maternity nurses regarding cardiotocography.

\section{Research Hypothesis:}

Maternity nurses' knowledge and practices regarding cardiotocography improved after the implementation of the educational program.

\section{Subjects and Method}

\section{Research design:}

A Quasi-experimental design (Timeseries design) was followed to fulfill the aim of this study.

\section{Settings:}

This study was conducted at Labor and CTG room of the Obstetrics and Gynecological Department at Benha University Hospital, which provides care during pregnancy, labor, postpartum, and gynecological problems for public clients.

\section{Sample:}

Sample type: A convenience sample was used.

Sample size: The sample size included (40) nurses who are working in the mentioned setting during the period of data collection.

\section{Tools of data collection:}

Two main tools were used for data collection:

Tool

(I):

Self-administered questionnaire: was designed by the researcher after reviewing related literature(Abd El-Razek, 2016). It was written in simple Arabic language and consisted of two parts:

Part (1): Demographic data of the studied nurses included age, years of experience, educational level, and attendance in any cardio-tocography training program.

Part (2): Nurses' knowledge regarding cardio-tocography which included (11) items.

\section{Scoring of knowledge:}

Each item was assigned scores (2) given when the answer was completely correct, a score (1) was given when the answer was incompletely correct and a score (0) was given when the answer was unknown. The total knowledge score was calculated by summation of the score of items. A total score of knowledge ranged from $(0-22)$. Nurses 


\section{Cardiotocography}

knowledge score was classified as the following:

- Poor when the total score $<60 \%$ equal $(0$ 13)

- Average when the total score $60 \%-<75 \%$ equal (14 - 16)

- Good when the total score $\geq 75 \%$ equal (17- 22)

Tool (II): Nurses' observational checklist regarding cardiotocography: This tool was designed by the researcher after reviewing related literature (El-Sayed, 2018), to assess nurses' practices during using the cardiotocography and composed of (4) procedures:

Preparatory phase procedure: Which included (9) items.

Action phase procedure: Included (11) items.

After 3 months follow-up phase procedure: Included (2) items.

Checklist about a reading of CTG trace procedure: Included 8 items.

\section{Scoring of observational checklists:}

Each item in preparatory phase procedure, action phase procedure, reading of CTG trace procedure and after 3 months follow-up phase procedure was given a score (1) when the item has been done and score (0) when the item has not been done. The total of each procedure of practice was calculated by summation of the score of items of (4) procedures. The total score for the practice of nurses ranged from (0-30). Nurses practice score was classified as the following:

- Unsatisfactory practice when the total score $<75 \%$ equal $(0-<22)$

- Satisfactory practice when the total score $\geq 75 \%$ equal (22-30)

\section{Tools validity and reliability:}

The validity of tools was ascertained by a panel of three experts in obstetrics nursing to test content validity and according to the expert's judgment; the comments advised to amend some questions, such as transfer the questions about CTG courses from the personal data to the nurses' knowledge. The questionnaire was modified relating to the clarity of sentences and appropriateness of the content.

Reliability of tools was done by Cranach alpha for test internal consistency for knowledge was equal 0.927 and for practice was equal 0.946 .

\section{Ethical considerations:}

Ethical aspects were considered before implementation of the study as the following: The aim of the study was explained to each nurse before applying the study. Oral consent was obtained from each nurse to participate in the study. The study was not having any physical, social, or psychological risks on the participant. Maintain confidentiality, and dignity of nurses. Freedom to withdraw from participation in the study at any time. The data was collected and treated confidentially

\section{Pilot study:}

The pilot study was carried out on 10 $\%$ (4 nurses) of the total sample to test the clarity, feasibility, and applicability of tools as well as to estimate the time needed for data collection and no modifications were done, nurses involved in the pilot study were included in the main study sample.

\section{Field work:}

To fulfill the aim of the present study, the following phases were adopted: interviewing, assessment, planning, implementation, and evaluation phase. These phases were carried out from the beginning of August 2019 and completed at the end of April 2020 covering 9 months. The researcher visited the previously mentioned setting three days/week (Tuesday, Wednesday, and Thursday) from 10 Am-2 Pm. 


\section{Interviewing and assessment phase:}

The researcher visited the previously mentioned setting and introduced himself, greet nurses, and all nurses were interviewed, the purpose of the study was explained by the researcher and oral consent was taken to participate in the study.

The researcher distributed a selfadministered questionnaire to nurses (tool I) to assess nurses' demographic data and evaluate knowledge regarding cardiotocography. As well as an observation checklist was used (tool. II) to assess nurses' practices regarding cardiotocography. The researcher interviewed about (5-6) nurses per week. The results of this phase are the baseline for further comparisons.

\section{Planning phase:}

Based on the results obtained from the preprogram assessment of nurse's knowledge and practice, the researcher designed the educational program and prepared a booklet in the Arabic language supported by figures after reviewing the related literature regarding cardiotocography. The researcher used different teaching methods such as lectures, group discussion, demonstration, and redemonstrations with the assistance of the instructional media as videos and instruction booklets, pictures about the trace of CTG.

\section{Implementation phase:}

The nurses were divided into 8 groups, each group (5 nurses) according to work circumstances, the educational program consisted of 5 sessions. The implementation phase was done for the nurses at the previously study mentioned setting for each group separately. Each group received 5 sessions (two theoretical and three practical). Each session took approximately 30-45 minutes. The implementation took about 9 weeks.

\section{Theoretical part:}

First session: this session aimed to emphasize rapport between nurses and researchers, identify the purpose of the program, and orient nurses about the program and its expected outcomes as well as describe the schedule and content of the program. In addition to teaching the nurses about the definition of the CTG, the important of CTG, the appropriate time for using CTG, and a maternal and fetal indication of CTG. A review and feedback from previous sessions, as well as the objectives of the new one, were delivered at the start of each session.

Second session: This session included teach the nurses about types of CTG, maternal position during the procedure of CTG, area to the application of CTG transducers, normal fetal heart rate, signs of fetal distress, and abnormal uterine contraction.

\section{Practical part:}

Third session: This session included training nurses about care and preparation of mothers for CTG, such as training the nurses to prepare necessary equipment: fetal monitor, ultrasound transducer, and either toco transducer (to assess uterine activity), ultrasonic coupling gel, and abdominal belt. As well as ensure standardized setting on a CTG machine to enable a consistent approach to teach and interpret EFM traces.

Training the nurses how to adopt a paper speed of 1 or $3 \mathrm{~cm}$ per minute, ensure that the date and time of setting on the CTG machine validated at the commencement of every CTG, put the label on CTGs with the mother's name, hospital number, date, and time of commencement, recorded and noted fetal heart rate on CTG. And explain the procedure to the mother and obtain permission to commence. In addition to suggest the woman empties the bladder. Put the mother in a Semi lateral position. 
Fourth session: Training the nurses how to perform Leopold's maneuver, align and insert the ultrasound transducer plug into the appropriate monitor port labeled "cardio" or "US" for an ultrasound, apply ultrasound coupling gel to the underside of the transducer placed on the maternal abdomen and place the transducer on the abdomen, preferably over the fetal back or below the level of the umbilicus in a full-term pregnancy of cephalic presentation or above the umbilicus in a fullterm pregnancy of breech presentation (Kelly et al., 2020).

Moreover, training the nurses to adjust the audio-volume control while moving the transducer over the abdomen, secure the ultrasound transducer with the abdomen belt or other fixation device, observe the indicator signal, which will flash simultaneously with each fetal heartbeat, set the record at 1, 2, or 3 $\mathrm{cm} / \mathrm{min}$ paper speed and observe the FHR on the stripe chart; obtain the base-line FHR between contractions or periodic change and check the time printed on the monitor stripe (reset monitor clock as necessary). Also periodically clean the transducer and maternal abdomen with a damp cloth to remove dried gel; reapply ultrasonic coupling gel and talcum powder to dust under the abdominal belt if this is the fixation device. Reposition the transducer whenever the fetal signal becomes unclear, such as when the mother moves or when the fetus descends in the pelvic (Zhu et al., 2021).

Fifth session: This session included training the nurses on how to reading CTG and differentiate between types of CTG trace: normal, reduced, and increased variability, acceleration, and deceleration (variable, early, late and prolonged). In addition to, training the nurses to sign and note the date, time, and mode of delivery on the CTG strips and stored securely with the woman's notes.

\section{Evaluation phase:}

Immediate immediat post-program and three months after the implementation educational program, the same format of preprogram tools were used to evaluate the effect of educational program on nurses' knowledge and practice

\section{Statistical analysis:}

Data were verified before computerized entry. The Statistical Packages for Social Science (SPSS version 25) was used for that purpose. Followed by data tabulation and analysis. Descriptive statistics were applied (e.g., mean, standard deviation, frequency, and percentage). Test of significance, (Chisquare test and Pearson correlation coefficient were used for quantitive data.

-No significant level value was considered when $\mathrm{p}>0.05$.

- A significant level value was considered when $\mathrm{p} \leq 0.05$.

- A highly significant level value was considered when $\mathrm{p} \leq 0.001$.

\section{Results}

Table (1): Demonstrates that more than half $57.5 \%$ of nurses were in age $20-29$ years, while less than a quarter $20.0 \%$ of nurses were in age $\geq 40$ years with the mean age $29.10 \pm 8.69$ years. Less than two-thirds $62.5 \%$ of nurses were technical nursing institute, and $30 \%$ were diploma. Besides, $40 \%$ of nurses were had less than 5 years of experience, while $22.5 \%$ of nurses were had more than 10 years of experience, with the mean years of experience was $6.85 \pm 4.07$ years. All of the nurses were not attending any training courses regarding cardiotocography.

Figure (1): Demonstrates that preimplementation of the educational program $87.5 \%$ of the studied nurses were had a poor level of knowledge, and $12.5 \%$ were had an average level. While through the immediat post-program and after 3 months follow-up 
$90.0 \%$ and $85.0 \%$ were had a good level of knowledge respectively.

Figure (2): Elucidates that $82.5 \%$ of nurses had unsatisfactory scores during the pretest, while during immediat post-program $90 \%$ of nurses had satisfactory practice, and the satisfactory practice was $80.0 \%$ during after 3 months follow-up.

Table (2): Shows that statistically significant difference between age and total score of knowledge during immediat postprogram and after 3 months follow-up with ( $\mathrm{p}=0.049$ and 0.007 ), with no statistically significant during preprogram $(\mathrm{p}=>0.05)$.

Regarding educational level table illustrates that a highly statistically significant difference between educational level and total score of knowledge during immediat postprogram with $(\mathrm{p}=0.001)$, with no statistically significant during preprogram and after 3 months follow-up ( $\mathrm{p}=>0.05)$.

$\mathrm{n}$ addition, years of experience bring to light a statistically significant difference between years of experience and total score of knowledge during after 3 months follow-up $(p=0.025)$. with no statistically significant during pre and immediat post-program $(\mathrm{p}=>0.05)$.
Table (3): Reveals that statistically significant difference between age and total score of practice during the immediat postprogram and after 3 months follow-up with $(\mathrm{p}=0.018$ and 0.002 ), with no statistically significant difference during preprogram $(\mathrm{p}=>0.05)$.

Table clarifies that statistically significant difference between the level of education and total score of practice during pre, immediat post-program with $\quad(p=0.000,0.017$, respectively. While no statistically significant difference during after 3 months follow$u p(p=>0.05)$.

In relevant to years of experience, the table shows that no statistically significant difference during pre, immediat postprogram, and after 3 months follow$u p(p>0.05)$.

Table (4): Shows that there was a significant positive correlation between the total score of nurses' knowledge and practice nurses' regarding cardiotocography during pre and post-implementation of educational program $(\mathrm{p}=<0.05$ and $<0.001)$. 
Effect of Educational Program on Knowledge and Practices of Maternity Nurses regarding Cardiotocography

Table (1): Distribution of the studied nurses according to demographic characteristics $(n=40)$

\begin{tabular}{|c|c|c|}
\hline Demographic Characteristics & NO. & $\%$ \\
\hline \multicolumn{3}{|l|}{ Age(years) } \\
\hline $20-29$ & 23 & 257.5 \\
\hline $30-39$ & 9 & 22.5 \\
\hline$\geq 40$ & 8 & 20.0 \\
\hline Mean \pm SD & $29.10 \pm 8.69$ & \\
\hline \multicolumn{3}{|l|}{ Educational Level } \\
\hline Nursing diploma & 12 & 30.0 \\
\hline Technical nursing Institute & 25 & 62.5 \\
\hline Bachelors in nursing & 2 & 5.0 \\
\hline Post graduate & 1 & 2.5 \\
\hline \multicolumn{3}{|l|}{ Experience Years } \\
\hline$<5$ & 16 & 40.0 \\
\hline $5<10$ & 15 & 37.5 \\
\hline$\geq 10$ & 9 & 22.5 \\
\hline Mean \pm SD & $6.85 \pm 4.07$ & \\
\hline \multicolumn{3}{|l|}{$\begin{array}{l}\text { Attendance any training } \\
\text { regarding cardiotocography }\end{array}$} \\
\hline $\mathrm{NO}$ & 40 & 100.0 \\
\hline
\end{tabular}

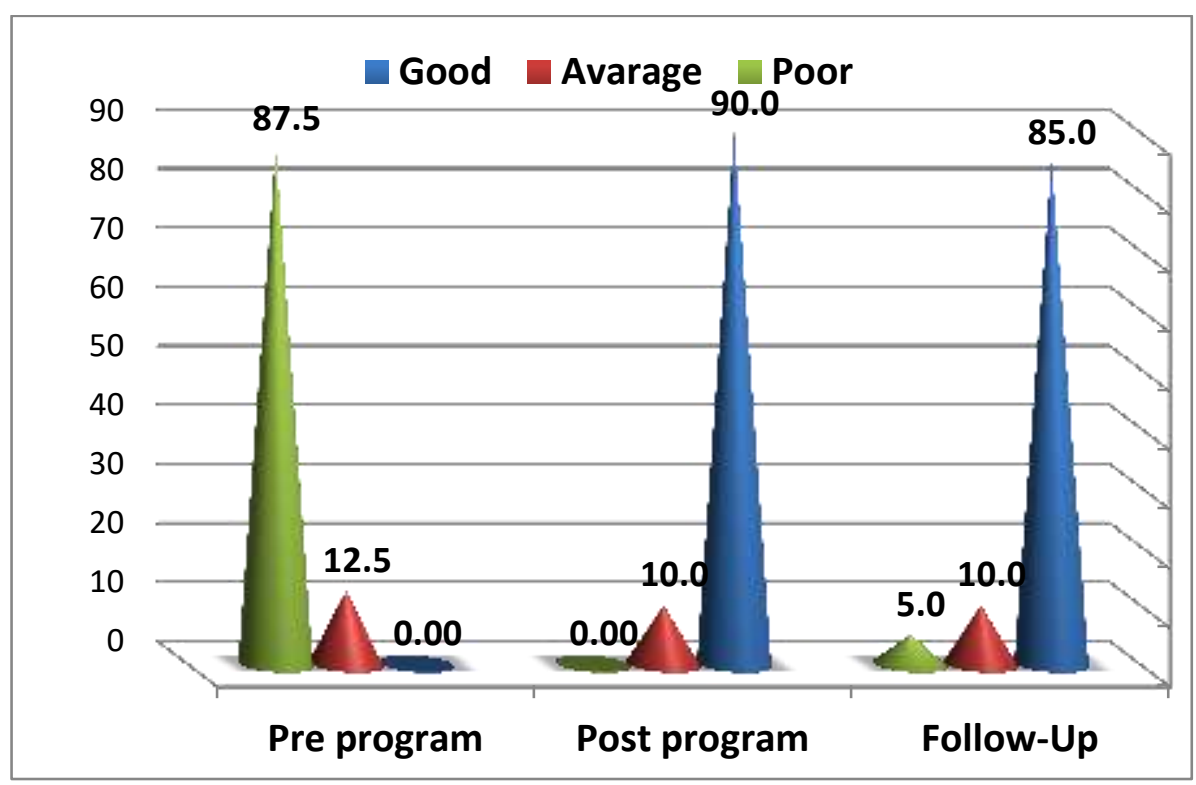

Figure (1): Distribution of nurses according to total level of knowledge regarding cardiotocography through pre, immediat post-program, and after 3 months follow-up of educational program implementation $(n=40)$. 


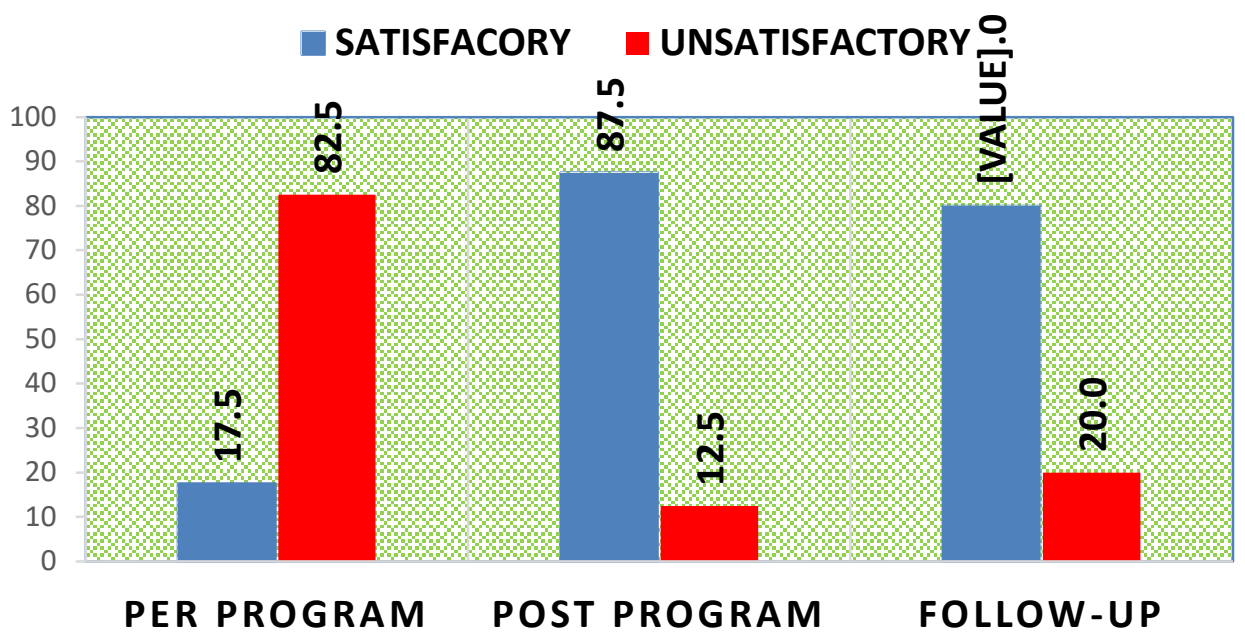

Figure (2): Distribution of nurses according to total score of practice regarding cardiotocography in pre, immediat post-program, and after 3 months follow-up $(n=40)$.

Table (2): Relation between demographic characteristics and total score of nurses' knowledge regarding cardiotocography $(n=40)$.

\begin{tabular}{|c|c|c|c|c|c|c|c|c|c|}
\hline \multirow{3}{*}{$\begin{array}{l}\text { Demographic } \\
\text { characteristics }\end{array}$} & \multicolumn{9}{|c|}{ Nurses' knowledge } \\
\hline & \multicolumn{3}{|c|}{ Pre program } & \multicolumn{3}{|c|}{ Immediat post-program } & \multicolumn{3}{|c|}{ After 3 months follow-up } \\
\hline & \begin{tabular}{l|} 
Good \\
No $(\%)$ \\
\end{tabular} & $\begin{array}{l}\text { Averag } \\
\text { No }(\%)\end{array}$ & $\begin{array}{l}\text { Poor } \\
\text { N }(\%) \\
\end{array}$ & \begin{tabular}{|l|} 
Good \\
No $(\%)$ \\
\end{tabular} & \begin{tabular}{|c|} 
Average \\
No $(\%)$ \\
\end{tabular} & \begin{tabular}{l|} 
Poor \\
No $(\%)$ \\
\end{tabular} & \begin{tabular}{|l|} 
Good \\
No $(\%)$ \\
\end{tabular} & \begin{tabular}{|c|} 
Average \\
No $(\%)$ \\
\end{tabular} & $\begin{array}{l}\text { Poor } \\
\text { No }(\%)\end{array}$ \\
\hline \multicolumn{10}{|l|}{ Age (years) } \\
\hline $20-29(n=23)$ & $0(0.00)$ & $4(17.4)$ & $19(82.6)$ & $23(100)$ & $0(0.00)$ & $0(0.00)$ & $23(100)$ & $0(0.00)$ & $0(0.00)$ \\
\hline \begin{tabular}{|l|}
$30-39(n=9)$ \\
\end{tabular} & $0(0.00)$ & $0(0.00)$ & $9(100)$ & $7(77.8)$ & $2(22.2)$ & $0(0.00)$ & 5(55.6) & $2(22.2)$ & $2(22.2)$ \\
\hline$>40(n=8)$ & $0(0.00)$ & $1(12.5)$ & $7(87.5)$ & $7(75.0)$ & $2(25.0)$ & $0(0.00)$ & $6(75.0)$ & $2(25.5)$ & $0(0.00)$ \\
\hline $\mathrm{X}^{2}$ & \multicolumn{3}{|c|}{1.789} & \multicolumn{3}{|c|}{6.049} & \multicolumn{3}{|c|}{13.954} \\
\hline p-value & \multicolumn{3}{|c|}{0.409} & \multicolumn{3}{|c|}{ 0.049* } & \multicolumn{3}{|c|}{$0.007 *$} \\
\hline \multicolumn{10}{|l|}{ Educational level } \\
\hline Diploma $(n=12)$ & $\begin{array}{l}0(0.00 \\
)\end{array}$ & $\begin{array}{c}3(25.0 \\
)\end{array}$ & $9(75.0)$ & $6(50.0)$ & $6(50.0)$ & $\begin{array}{l}0(0.00 \\
)\end{array}$ & $9(75.0)$ & $3(25.0)$ & $0(0.00)$ \\
\hline $\begin{array}{l}\text { Technical } \\
\text { Nursing } \\
\text { Institute }(n=25)\end{array}$ & $\begin{array}{l}0(0.00 \\
)\end{array}$ & $\begin{array}{c}7(28.0 \\
)\end{array}$ & $\begin{array}{c}18(72.0 \\
)\end{array}$ & $25(100)$ & $0(0.00)$ & $\begin{array}{l}0(0.00 \\
)\end{array}$ & $\begin{array}{l}24(96.0 \\
)\end{array}$ & $1(4.0)$ & $0(0.00)$ \\
\hline Bachelor $(n=2)$ & $\begin{array}{l}0(0.00 \\
)\end{array}$ & $2(100)$ & $0(0.00)$ & $2(100)$ & $0(0.00)$ & $\begin{array}{l}0(0.00 \\
)\end{array}$ & $2(100)$ & $0(0.00)$ & $0(0.00)$ \\
\hline $\begin{array}{l}\text { Post graduate } \\
(n=1)\end{array}$ & $\begin{array}{l}0(0.00 \\
)\end{array}$ & $1(100)$ & $0(0.00)$ & $1(100)$ & $0(0.00)$ & $\begin{array}{l}0(0.00 \\
)\end{array}$ & $1(100)$ & $0(0.00)$ & $0(0.00)$ \\
\hline $\mathbf{X}^{2}$ & \multicolumn{3}{|c|}{6.769} & \multicolumn{3}{|c|}{16.471} & \multicolumn{3}{|c|}{4.333} \\
\hline p -value & \multicolumn{3}{|c|}{0.080} & \multicolumn{3}{|c|}{$0.001 * *$} & \multicolumn{3}{|c|}{0.228} \\
\hline \multicolumn{10}{|c|}{ Years of experience } \\
\hline$<5(n=16)$ & $0(0.00)$ & $7(43.8)$ & $9(56.3)$ & $15(93.8)$ & $1(6.3)$ & $0(0.00)$ & $16(100)$ & $0(0.00)$ & $0(0.00)$ \\
\hline $5-10(n=15)$ & $0(0.00)$ & $3(20.0)$ & $12(80.0)$ & $13(86.7)$ & $2(13.3)$ & $0(0.00)$ & $11(73.3)$ & $4(26.7)$ & $0(0.00)$ \\
\hline$>10(n=9)$ & $0(0.00$ & $3(33.3)$ & $6(66.7)$ & $6(66.7)$ & $3(33.3)$ & $0(0.00)$ & $9(100)$ & $0(0.00)$ & $0(0.00)$ \\
\hline $\mathbf{X}^{2}$ & \multicolumn{3}{|l|}{1.994} & \multicolumn{3}{|c|}{3.366} & \multicolumn{3}{|c|}{7.407} \\
\hline p- value & \multicolumn{3}{|c|}{0.369} & \multicolumn{3}{|c|}{0.186} & \multicolumn{3}{|c|}{$0.025 *$} \\
\hline
\end{tabular}

* Statistically significant difference $(\mathrm{p} \leq 0.05) * *$ A highly statistically significant difference $(\mathbf{p} \leq \mathbf{0 . 0 0 1})$ 
Effect of Educational Program on Knowledge and Practices of Maternity Nurses regarding Cardiotocography

Table (3): Relation between demographic characteristics and total score of nurses' practices regarding cardiotocography $(n=40)$.

\begin{tabular}{|c|c|c|c|c|c|c|}
\hline \multirow{3}{*}{$\begin{array}{l}\text { Demographic } \\
\text { characteristics }\end{array}$} & \multicolumn{6}{|c|}{ Nurses' practice } \\
\hline & \multicolumn{2}{|r|}{ Pretest } & \multicolumn{2}{|c|}{ Immediat post-progr: } & \multicolumn{2}{|c|}{ After 3 months follow } \\
\hline & $\begin{array}{c}\text { Satisfactory } \\
\mathrm{N}(\%)\end{array}$ & $\begin{array}{c}\text { Unsatisfact } \\
\mathrm{N}(\%)\end{array}$ & $\begin{array}{c}\text { Satisfactory } \\
\mathrm{N}(\%)\end{array}$ & $\begin{array}{c}\text { Unsatisfact } \\
\mathrm{N}(\%)\end{array}$ & $\begin{array}{c}\text { Satisfactor. } \\
\mathrm{N}(\%)\end{array}$ & $\begin{array}{c}\text { Unsatisfacto } \\
\mathrm{N}(\%)\end{array}$ \\
\hline \multicolumn{7}{|l|}{ Age (years) } \\
\hline $20-29(n=23)$ & $1(4.3)$ & $22(95.7)$ & $23(100)$ & $0(0.00)$ & $22(95.7)$ & $1(4.3)$ \\
\hline 30- $39(n=9)$ & $1(11.9)$ & $8(88.9)$ & $6(66.7)$ & $3(33.3)$ & $7(77.8)$ & $2(22.2)$ \\
\hline$>40(n=8)$ & $0(0.00)$ & $8(00)$ & $6(75.0)$ & $2(25.0)$ & $3(37.5)$ & $5(62.5)$ \\
\hline $\mathrm{X}^{2}$ & \multicolumn{2}{|c|}{1.149} & \multicolumn{2}{|c|}{8.0000} & \multicolumn{2}{|c|}{12.581} \\
\hline p value & \multicolumn{2}{|c|}{0.563} & \multicolumn{2}{|c|}{ 0.018* } & \multicolumn{2}{|c|}{$0.002 * *$} \\
\hline \multicolumn{7}{|l|}{ Educational level } \\
\hline Diploma $(n=12)$ & $0(0.00)$ & $12(100)$ & $11(91.7)$ & $1(8.3)$ & $1(8.3)$ & $11(91.7)$ \\
\hline $\begin{array}{l}\text { Technical } \\
\text { Nursing } \\
\text { Institute }(n=25)\end{array}$ & $0(0.00)$ & $25(100)$ & $25(100)$ & $0(0.00)$ & $7(28.0)$ & $18(72.0)$ \\
\hline Bachelor $(n=2)$ & $1(50.0)$ & $1(50.0)$ & $1(50.0)$ & $1(50.0)$ & $0(0.00)$ & $2(100)$ \\
\hline $\begin{array}{l}\text { Post graduate } \\
(n=1)\end{array}$ & $1(100)$ & $0(0.00)$ & $1(100)$ & $0(0.00)$ & $0(0.00)$ & $1(100)$ \\
\hline $\mathbf{X}^{2}$ & \multicolumn{2}{|c|}{29.474} & \multicolumn{2}{|c|}{$1 / 175$} & \multicolumn{2}{|c|}{2.771} \\
\hline p-value & \multicolumn{2}{|c|}{$0.000 * *$} & \multicolumn{2}{|c|}{$0.017 *$} & \multicolumn{2}{|c|}{0.428} \\
\hline \multicolumn{7}{|c|}{ Years of experience } \\
\hline$<5(n=16)$ & $1(6.2)$ & $15(93.8)$ & $15(93,8)$ & $1(6.2)$ & $12(75.0)$ & $4(25.0)$ \\
\hline $5-10(n=15)$ & $1(6.7)$ & $14(93.3)$ & $15(100)$ & $0(0.00)$ & $13(86.7)$ & $2(13.3)$ \\
\hline$>10(n=9)$ & $0(0.00)$ & $9(100)$ & $8(88.9)$ & $1(11.1)$ & $7(77.8])$ & $2(22,2)$ \\
\hline $\mathrm{X} 2$ & \multicolumn{2}{|c|}{0.614} & \multicolumn{2}{|c|}{1.550} & \multicolumn{2}{|c|}{0.694} \\
\hline p-value & \multicolumn{2}{|c|}{0.736} & \multicolumn{2}{|c|}{0.461} & \multicolumn{2}{|c|}{0.707} \\
\hline
\end{tabular}

* Statistically significant difference $(\mathbf{p} \leq \mathbf{0 . 0 5}) * *$ A highly statistically significant difference $(\mathbf{p} \leq \mathbf{0 . 0 0 1})$

Table (4) Correlation between total score of nurses' knowledge and practice regarding cardiotocography through different phases of educational program implementation $(n=40)$

\begin{tabular}{|c|c|c|c|c|c|c|c|}
\hline & \multirow{3}{*}{ variables } & \multicolumn{6}{|c|}{ Total knowledge score } \\
\hline & & \multicolumn{2}{|c|}{ preprogram } & \multicolumn{2}{|c|}{$\begin{array}{c}\text { Immediat post- } \\
\text { program }\end{array}$} & \multicolumn{2}{|c|}{$\begin{array}{l}\text { After } 3 \text { months } \\
\text { follow-up }\end{array}$} \\
\hline & & $\mathbf{r}$ & p & $\mathbf{r}$ & $\mathbf{p}$ & $\mathbf{r}$ & p \\
\hline \multirow{3}{*}{$\begin{array}{c}\text { Total } \\
\text { practice } \\
\text { score }\end{array}$} & preprogram & 0.361 & $0.022^{*}$ & & & & \\
\hline & $\begin{array}{c}\text { Immediat post- } \\
\text { program }\end{array}$ & & & 0.497 & $0.001^{* *}$ & & \\
\hline & $\begin{array}{l}\text { After } 3 \text { months } \\
\text { follow-up }\end{array}$ & & & & & 0.718 & $0.000^{* *}$ \\
\hline
\end{tabular}

* Statistically significant difference $(\mathbf{p} \leq \mathbf{0 . 0 5}) * *$ A highly statistically significant difference $(\mathbf{p} \leq \mathbf{0 . 0 0 1})$ 


\section{$\underline{\text { Saleh Zaghir, Soad Abd-Elsalam, Hend Abdallah, and Samah Abdelhaliem }}$}

Discussion

Cardiotocography is the method most used in prenatal diagnostic for the surveillance of fetal well-being both in the antepartum and in the intrapartum period (Saccone et al., 2021). The maternity nurse plays an imperative role in providing information about fetal monitoring, its effectiveness in low-risk women, and its advantages and limitations. The responsibility of nurses assesses patterns of fetal heart rate, implement independent nursing interventions, and report non-reassuring patterns to the physician regularly to assess and record results of electronic fetal monitoring to provide a consistent and timely evaluation of fetal well-being and progress of labor (Ekengård et al., 2021).

Furthermore, nowadays the main focus of maternal and fetus health is towards the evaluation of fetal health to assess fetal well-being. A majority of $80 \%$ of fetal death occurs in the antepartum period due to many causes which include chronic fetal hypoxia, intrauterine growth retardation, maternal complications, diabetes mellitus, hypertension, infection, and fetal congenital malformation. Early information about fetal well-being is one of the fundamental goals of fetal monitoring either during pregnancy or labor (Chou et al., 2021).

The present study was aimed to evaluate the effect of educational programs on the knowledge and practices of maternity nurses regarding cardiotocography. The findings of the current study are presented under four sections, demographic characteristics, nurses' knowledge and practice regarding cardiotocography in different phases of implementing the educational program, and correlation and relation between study variables.
Regarding

demographic characteristics of studied nurses, the present study results revealed that more than half of nurses' age was from 20-29 years with mean age $29.10 \pm 8.69$. The results were in accordance with the study of Abd El-Razek, (2016), who studied "the effect of educational programs about methods of assessing fetal well-being during pregnancy among nurses", Jordan, who reported that more than one-third of the sample was $20-30$ years. Also, the study of Oleiwi, (2018), who studied "the Effectiveness of an Education Program Concerning Cardiotocography on NurseMidwife's knowledge in Maternity Hospitals" at Baghdad City, Iraq showed that the highest percentage of nurses -midwives in the study group were (25-29) years old.

Concerning educational level, the results of the present study clarified that more than half of nurses had a technical nursing institute, the present study finding disagreed with Rosy, (2018), who studied" the effect of planned teaching program on cardiotocography among midwives in Alappuzha", India, showed that the majority of midwives who were participated in the study had professional educational qualification up to general nursing and midwifery. The current findings were in disagreement with El-Sayed, (2018), who studied "the effect of educational sessions about cardio-tocography on nurse's knowledge and skills at labor and high-risk units" Egypt, who reported that more than two-thirds of nurses had a diploma.

Regarding years of experience, the findings of the present study showed that more than one-third of nurses had less than five years of experience with a mean of $6.85 \pm 4.07$, the finding is supported by the study of Thellesen et al., (2018) who studied the development of a written assessment for a 
national Interprofessional cardiotocography education program, and showed that near to one-third of nurses had less than five years of experience. Besides, Oleiwi, (2018), reported that about one-third of nurses had less than five years of experience.

Regarding knowledge of studied nurses regarding cardiotocography, the results of the present study showed that the majority of the studied nurses had a poor knowledge regarding cardiotocography preprogram. This may be due to all studied nurses not have any training courses regarding cardiotocography.

This study finding is in line with Said and Ali, (2020), who studied "the effect of supportive nursing instructions for maternity nurses regarding electronic fetal monitoring", Egypt, and revealed that the majority of nurses had poor total scores during the preprogram. Also, the finding of this study supported by Sowmya et al., (2018), who studied "the effectiveness of cardiotocography training program on knowledge and skill among nurses working in maternity units" India, found that level of nurses' knowledge on general facts on cardiotocography, had an inadequate level of knowledge in the preprogram.

On the other hand, throughout the immediat post-program the majority of nurses had a good total score of knowledge, this improvement in nurse's knowledge during immediat post-program revealed that the effectiveness of the educational program, and the nurses become aware and able to dealing with cardiotocography. During the after 3 months follow-up most common of nurses still had a good total score of knowledge with a slight decline in nurse's knowledge due to nurses' retention of knowledge. But in general, all items of knowledge regarding cardiotocography were improved after the implementation of the educational program.
This study finding is in line with Thellesen et al., (2018), who studied " Cardiotocography interpretation skills and the association with the size of the maternity unit, years of obstetric work experience and healthcare professional background" who reported that more than half of nurses had good total score during immediat postprogram. Also, the finding of this study supported by Sowmya et al., (2018) mentioned that in the immediat post-program majority of nurses had an adequate level of knowledge.

The current finding is relatively similar to the study of Abd El-Razek, (2016), which studied the "assessment of the staff nurse's knowledge pre and immediat postprogram about electronic fetal monitoring" and revealed that staff nurses had higher knowledge on the immediat post-program than on preprogram. The present finding is also relatively in accordance with the study of Rosy, (2018), which showed the improvement in knowledge means of midwives after a planned teaching program.

This result disagrees with Bayley et al., (2016) who studied "Knowledge and perceptions of quality of obstetric and newborn care of local health providers, Malawi," reported that training had little impact on levels of knowledge and the gap of knowledge couldn't be overcome by simply providing more training, so most of the staff reported perception of poor quality of care.

Relevant to the total score of nurses' practices, the results of the current study showed that most common of studied nurses were had unsatisfactory scores during preprogram, this unsatisfactory practice was due to poor knowledge of nurses regarding cardiotocography and before implementation of educational program the nurses were 
believed that cardiotocography is an invasive procedure only performed by the physician.

This study in line with Ibrahim and Arief., (2019), who studied "Effect of electronic fetal monitoring educational program on knowledge and interpretations of internship nursing student", Assiut, Egypt and clarified that more than three-quarters of studied nurses have an unsatisfactory practice before supportive nursing instructions.

While, during the immediat postprogram, and after 3 months follow-up most common nurses were had satisfactory scores. This improvement may be related to improved nurses' knowledge regarding cardiotocography leads to improve the performance of the nurses. Also due to the effectiveness of the educational program. In addition, after the implementation of educational program, the nurses were becoming aware of the nursing role in cardiotocography procedure.

The current study results were in the same line with El-Sayed, (2018), who revealed significant improvements were found among preprogram, immediate immediat post-program, and after 3months immediat post-program. Also, the finding of this study is in agreement with Kelly et al., (2020), who studied training in the use of intrapartum electronic fetal monitoring with cardiotocography, who revealed a highly statistically significant difference before and after training instructions during fetal monitoring procedures.

Also, the current study finding is similar to the study of Ramadan et al., (2018). Who studied "the maternity nurses' performance regarding non-invasive fetal wellbeing measures: educational intervention", Egypt, showed a significant improvement in the total level of nurses, practice regarding Noninvasive fetal wellbeing measures when compared with pre and immediat post-program implementation.

Also, Rizk and Hafez, (2016) who studied "the effect of an interactive computerbased simulator on a nurse' performance about electronic fetal heart rate monitoring" reported that there is a highly statistically significant improvement noticed among the intervention group regarding performance after the intervention.

On investigating the ability of nurses to interpretation of cardiotocography tracing during different phases of educational program implementation, the finding of the current study revealed that most common of nurses during the preprogram had an unsatisfactory score. While after implementation of educational programs the most common of nurses were had satisfactory scores. Besides, the common of nurses in the after 3 months follow-up tests had a satisfactory score. This finding reflects the importance of educational program as a cornerstone element in improving knowledge and practice. Therefore, there is a need for continuous education programs for nurses to increase awareness about this issue.

The current finding agreed with the study of Parhizkar et al., (2015), who studied "midwifery nurses' skill to interpret cardiotocograph Iran, revealed inadequate knowledge of respondents regarding interpretation and diagnosis of the different graph in CTG".

Regarding the relation between demographic characteristics and total score of nurses' knowledge, the finding of the present study showed significant differences among studied nurse's total score of knowledge and nurses' demographic characteristics. Age, all nurses of the age group of 20-29 years were had good knowledge score during immediat post-program and after 3 months follow-up, 
that due to the young age is abler and eager to learn, On the contrary of age groups who were more than 40 years tend to obtain less score during after 3 months follow-up. Educational level, highly statistically significant was found between educational level and immediat post-program knowledge score, Where The higher the educational level the more tend to had high total knowledge score. years of experience, statistically significant was found between years of experience and after 3 months follow-up knowledge score.

These results indicated health knowledge was much stronger. The researcher's point of view suggests giving staff members opportunities to assume roles beyond primary responsibility, gain new skills and knowledge to work, access to the session for learning new things encourage, feeling of achievement. It also increases motivation to further expand skills. The educational program was effective in raising staff nurse awareness. The program showed a significant impact increase of the participant's level of knowledge which reinforce the continuing need for more education about cardiotocography.

This result is in line with Parhizkar et al., (2015), who mentioned there was a significant association between education level and knowledge on CTGs interpretation. Results of the current study in harmony with Kelly et al., (2020), who revealed that there was a highly statistically significant difference between studied nurses' total knowledge score, and nurses' personnel characteristics. Moreover, the finding of the present study is in contact with Sangeetha, (2015), who studied "assess knowledge attitude and practice regarding Cardiotocography among staff", who found that there is a significant difference between knowledge on interpretation of CTG and respondents' educational level and work experience.

This result is in agreement with Ramadan et al., (2018), who reported that no significant difference between age and total knowledge score and a highly statistically significant difference between educational qualification and total score of knowledge?

On the other hand, this study is in disagreement with Lamé et al., (2019) who studied improving the practice of intrapartum electronic fetal heart rate monitoring with cardiotocography for safer childbirth, who showed that no significant difference between the total score of knowledge and years of experience. This study is in dispute with Sowmya et al., (2018), who found that no significant association between demographic variables with the level of knowledge among staff nurses in preprogram and immediat postprogram. study findings were in disagreement with Pushpaveni, (2015), who evaluate the effect of the self-instructional module on fetal wellbeing measures among nurses and showed that no significant association between level of knowledge regarding CTG and any of the demographic data of the nurses.

Regarding the relation between nurses' practice total score and demographic characteristics, the results of the present study indicate that there was a significant difference among studied nurses' total practice score and nurses' age and level of education. On the other hand, there was no statistically significant difference between nurses' years of experience and total practice scores. This improvement may be related to the effective training program and also due to improved nurses' knowledge regarding CTG lead to improve the performance of the nurses. This finding may be due to the fact that nurses 
believe that cardiotocography is a procedure only performed by the physician. However, after the implementation of the program, the nurses realized nursing role in this procedure.

This study is in line with Ramadan et al., (2018). showed that that there was a highly statistically significant difference between educational qualification and total practice score. In line with this finding Sukumaran et al., (2021), who studied "Cardiotocography versus intermittent auscultation of fetal heart on admission to labor ward for assessment of fetal wellbeing" and found there was a highly statistically significant relationship between nurses' practice and age. Additionally, this study results contact with. The current study finding not matched with Sowmya et al., (2018), who denoted that there was no significant association between the level of skill with selected demographic variables among nurses.

Moreover, the finding of the current study showed a significant positive correlation between nurses' knowledge and practice before and after implementation of educational program regarding cardiotocography. That's maybe related to the improvement of nurses' practice in relation to the improvement of nurses' knowledge in different phases of implementation of the educational program. This finding is in agreement with Lamé et al., (2019), who conducted that there was an improvement in nurses' practice in relation to improving nurses' knowledge in pre and postimplementation of program. Also result of the current study is in line with Said and Ali, (2020), who mentioned a statistically significant correlation between the total scores of maternity nurses' knowledge and practices before and after nursing supportive instructions.
Also, this study is in line with Thellesen et al., (2018), who reported highly significant positive correlations were found between the level of knowledge and skills of nurses regarding CTG. This may be explained by providing CTG training to increase the frequency of performing CTG for practices that improve the quality of CTG for pregnant women.

\section{Conclusion}

The educational program was effective in improving the level of knowledge and practice of maternity nurses regarding cardio-tocography. There was a significant improvement in the total score of nurses' knowledge and practice regarding cardiotocography when comparing pre and after implementation of the educational program, with a slight decline after three months of educational program. Furthermore; a significant positive correlation between the total score of knowledge and practice. Therefore, the study aim was achieved and the research hypothesis was supported.

\section{Recommendations}

- Applying continuous in-service training program for maternity nurses to improve performance regarding cardiotocography.

- $\quad$ Periodic evaluation of knowledge and practices for maternity nurses to assess what needs and appraisals regarding cardiotocography.

\section{- Regarding further studies,}

- Effect of educational program on nurses' efficacy about cardiotocography.

- Effect of educational program on knowledge and attitudes of pregnant women about cardio-tocography

- Education programs should be provided for all newly maternity nurses about Cardiotocography. 


\section{References}

Abd El-Razek, A. (2016). Impact of educational programs about methods of assessment of fetal wellbeing during pregnancy among staff nurses. Open Journal of Obstetrics and Gynecology, 6(08), 473.

Arief, A. F., Ibrahim, W. H., (2019). Effect of Electronic Fetal Monitoring Educational Program on Knowledge and Interpretations of Internship Nursing Students. International Journal of Novel Research in Healthcare and Nursing Vol. 6, Issue 1, pp: (384-395).

Bayley, O., Colbourn, T., Nambiar, B., Costello, A., Kachale, F., Meguid, T., \& Mwansambo, C. (2016). Knowledge and perceptions of quality of obstetric and newborn care of local health providers: a cross-sectional study in three districts in Malawi. Malawi medical journal, 25(4), 105108.

Bertrand, J., \& Consortium, I (2019). Interventions for children with fetal alcohol spectrum disorders (FASDs): overview of findings for five innovative research projects. Research in developmental disabilities, 30(5), 986-1006.

Blix, E., Maude, R., Hals, E., Kisa, S., Karlsen, E., Nohr, E. A., Reinar, L. M. (2019). Intermittent auscultation fetal monitoring during labour: A systematic scoping review to identify methods, effects, and accuracy. PloS one, 14(7), e0219573.

Cecil, R. (2020). Introduction: An insignificant event? Literary and anthropological perspectives on pregnancy loss. In the Anthropology of Pregnancy Loss (pp. 1-14).

Chou, F.S., Newton, K., \& Wang, P.S. (2021). Quantifying Fetal Reprogramming for Biomarker Development in Era of HighThroughput Sequencing. Genes, 12(3), 329.

Ekengård, F., Cardell, M., \& Herbst, A. (2021). Impaired validity of the new FIGO and Swedish CTG classification templates to identify fetal acidosis in the first stage of labor. The Journal of Maternal-Fetal \& Neonatal Medicine, 1-8.

El-Sayed, H. E. S. M., \& Saadoon, O. H. M. M. (2018). Effect of Educational Sessions About Cardiotocography On Nurses
Knowledge and Skills at Labor and High-Risk Units. IOSR Journal of Nursing and Health Science, 7(3), 34-41.

Holmgren, C. (2020). Interpretation of Fetal Heart Rate Monitoring in the Clinical Context. Clinical obstetrics and gynecology, 63(3), 625-634.

Kahveci, B., Melekoglu, R., Evruke, I. C., \& Cetin, C. (2018). The effect of advanced maternal age on perinatal outcomes in nulliparous singleton pregnancies. BMC pregnancy and childbirth, 18(1), 343.

Kelly, S., Redmond, P., King, S., OliverWilliams, C., Lamé, G., Liberati, E., ... \& Burt, J. (2020). Training in the use of intrapartum electronic fetal monitoring with cardiotocography: systematic review and meta-analysis. BJOG: An International Journal of Obstetrics \& Gynaecology, 128(9), 1408-1419.

Lamé, G., Liberati, E., Burt, J., Draycott, T., Winter, C., Ward, J., \& Dixon-Woods, M. (2019). IMproving the practice of intrapartum electronic fetal heart rate MOnitoring with cardiotocography for safer childbirth (the IMMO programme): protocol for a qualitative study. BMJ open, 9(6), e030271.

Oleiwi, S. (2018). Effectiveness of an Education Program Concerning Cardiotocography on Nurses-Midwives Practice in Maternity Hospitals at Baghdad City. Iraqi National Journal of Nursing Specialties, 1(31), 24-34.

Parhizkar, S., Latiff, L. A., \& Aman, N. B. (2015). Midwifery Nurses' Skill to Interpret Cardiotocogram: A Cross Sectional Study. International journal of healthscience and research, 1-6.

Pushpaveni, N. (2015). Effect of SelfInstructional Module on Foetal Well-being Measures among Nurses in Bengaluru. Nursing Journal of India, 103(5), 236.

Ramadan, S. A. E., Mohamed, A. I., \& Salama, A. M. (2018). Maternity Nurses' Performance Regarding Non-invasive Fetal Wellbeing Measures: Educational Intervention, Journal of Nursing and Health Science, 2320-1959.p- ISSN: 2320-1940 
Volume 7, Issue 1 Ver. VI. (Jan.- Feb .2018), PP 08-19

Richards, D. S. (2020). Unusual Circumstances and Additional Procedures for Fetal Evaluation in Labor. Clinical obstetrics and gynecology, 63(3), 645-658.

Rizk, S. A., \& Hafez, S. K. (2016). Effect of an Interactive Computer-based Simulators Training Program on Nurses' Performance Regarding Electronic Fetal Heart Rate Monitoring, Life Sci J 2016; 10 (2): 2940-2948.

Rodgers, C. C. (2020). Continuous electronic fetal monitoring during prolonged labor may be a risk factor for having a child diagnosed with autism spectrum disorder. Medical Hypotheses, 145, 110339.

Rosy, M. M., (2018). Effect of Planned Teaching Programme on cardiotocography among Midwives in Alappuzha. 2018, 5(05), 7. doi: 10.15520/ ijnd. 2018. vol5.iss 05.59.39-45.

Saccone, G., Tagliaferri, S., Grasso, A., Ascione, R., Esposito, G., Esposito, F. G., \& Zullo, F. (2021). Antenatal cardiotocography with and without computer analysis in highrisk pregnancy: a randomized clinical trial. American Journal of Obstetrics \& Gynecology MFM, 3(1), 100284.

Said, A. R., \& Ali, H. A. (2020). Effect of Supportive Nursing Instructions for Maternity Nurses Regarding Electronic Fetal Monitoring. International Journal of Nursing, 10(1), 1-11.

Sangeetha, C. (2015). Assess knowledge attitude and practice regarding Cardiotocography amonge staff. Bangalora no (258/A), 99.

Sergi, C. M. (2020). Placenta, Abnormal Conception, and Prematurity. In Pathology of Childhood and Adolescence (pp. 1409-1569).
Sowmya, M., Priya, G., Ramesh, C., \& Jothi, K. (2018). Effectiveness of Cardiotocography Training Programme on knowledge and skill among nurses working in maternity units. Nitte University Journal of Health Science, 3(4), 87.

Sukumaran, S., Pereira, V., Mallur, S., \& Chandraharan, E. (2021). Cardiotocograph CTG) changes and maternal and neonatal outcomes in chorioamnionitis and/or funisitis confirmed on histopathology. European Journal of Obstetrics \& Gynecology and Reproductive Biology, 260, 183-188.

Tamber, K. K., Hayes, D. J., Carey, S. J., Wijekoon, J. H., \& Heazell, A. E. (2020). A systematic scoping review to identify the design and assess the performance of devices for antenatal continuous fetal monitoring. PloS one, 15(12), e0242983.

Thellesen, L., Sorensen, J. L., Hedegaard, M., Rosthoej, S., Colov, N. P., Andersen, K. S., \& Bergholt, T. (2018). Cardiotocography interpretation skills and the association with size of maternity unit, years of obstetric work experience and healthcare professional background: a national cross-sectional study. Acta obstetricia et gynecologica Scandinavica, 96(9), 1075-1083.

Visser, G. H., \& Ayres-de-Campos, D. (2017). FIGO consensus guidelines on intrapartum fetal monitoring: Adjunctive technologies. International Journal of Gynecology \& Obstetrics, 131(1), 25-29.

Wisner, K., \& Holschuh, C. (2018). Fetal heart rate auscultation. Nursing for Women's Health, 22(6), e1-e32.

Zhu, L. A., Blanc, J., Heckenroth, H., Peyronel, C., Graesslin, B., Marcot, M., \& Bretelle, F. (2021). Fetal physiology cardiotocography training, a regional evaluation. Journal of Gynecology Obstetrics and Human Reproduction, 50(6), 102039. 
تأثيربرنامج تعليمي على معلومات وممارسات ممرضات الامومه المتعلقة بجهاز مراقبة نبض

\section{الجنين}

صالح صغير محمد الهتار - سعاد عبدالسلام رمضان- هند عبدالله السيد عفيفي- سماح عبدالحليم سعيد إبر اهيم

يعد جهاز مر اقبة نبض الجنين هو الأداة الأكثر شيوعًا لتقييم الجنين قبل واثناء الو لادة من اجل اكتثاف أي تغييرات غير طبيعية قد تحدث والتي تعرض الجنين لخطر نقص الاكسجين أو الوفاة بسبب نقص الأكسجين لذلك يجب أن تكون ممرضات الامومة على دراية كاملة بالحالات الطبيعية والغير طبيعية التي يسجلها جهاز مر اقبة نبض الجنين وكيفية التعامل معها.لذلك هدفت الدراسة إلى تقييم فعالية برنامج تعليمي فيما يتعلق بجهاز مر اقبة نبض الجنين على معلومات وممارسات ممرضات الأمومة بمستثفى بنها الجامعي و عددهم • ؛ ممرضئ.

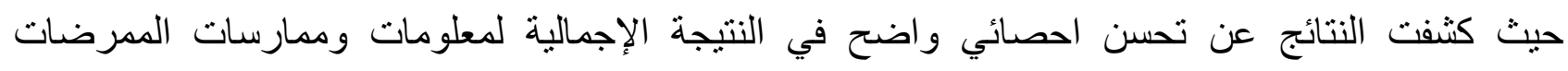

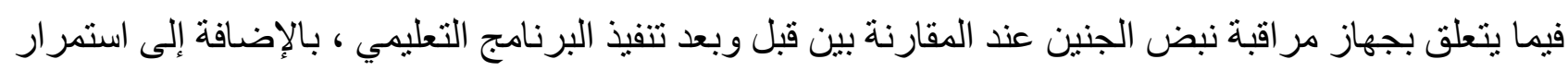

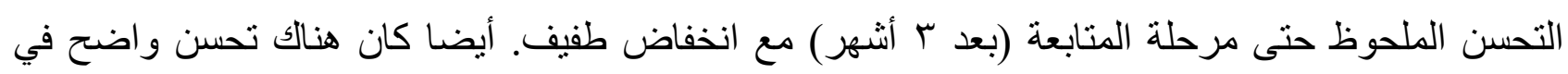

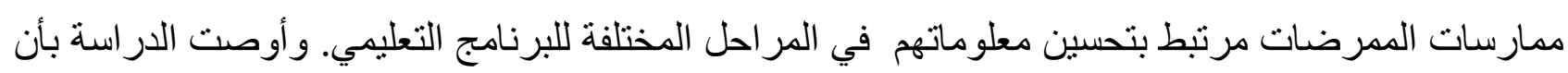
هناك حاجة الى نطبيق برنامج التدريب المستمر لممرضات الأمومة لتحسين إدائهم فيما يتعلق بجهاز مر اقبة فئة نبض الجنينو ايضاً التقييم الدوري لمعلومات وممارسات ممرضات الأمومة لتقيبم الاحتباجات و الثقييمات المتعلقة بجهاز مر اقبة نبض الجنين. 